Marquette University

e-Publications@Marquette

Biomedical Engineering Faculty Research and

Publications

Biomedical Engineering, Department of

$1-2016$

\title{
Automated Selection of the Optimal Cardiac Phase for Single- Beat Coronary CT Angiography Reconstruction
}

Daniel Stassi

Marquette University

S. Dutta

GE Healthcare

H. Ma

Marquette University

A. Soderman

GE Healthcare

D. Pazzani

GE Healthcare

See next page for additional authors

Follow this and additional works at: https://epublications.marquette.edu/bioengin_fac

\section{Recommended Citation}

Stassi, Daniel; Dutta, S.; Ma, H.; Soderman, A.; Pazzani, D.; Gros, E.; Okerlund, D.; and Gilat-Schmidt, Taly, "Automated Selection of the Optimal Cardiac Phase for Single-Beat Coronary CT Angiography

Reconstruction" (2016). Biomedical Engineering Faculty Research and Publications. 407.

https://epublications.marquette.edu/bioengin_fac/407 


\section{Authors}

Daniel Stassi, S. Dutta, H. Ma, A. Soderman, D. Pazzani, E. Gros, D. Okerlund, and Taly Gilat-Schmidt 


\title{
Automated Selection of the Optimal Cardiac Phase for Single-Beat Coronary CT Angiography Reconstruction
}

\author{
D. Stassi \\ Milwaukee, WI \\ S. Dutta \\ GE Healthcare, \\ Waukesha, WI \\ H. Ma \\ Milwaukee, WI
A. Soderman
GE Healthcare, Waukesha, WI
D. Pazzani
GE Healthcare, Waukesha, WI

Department of Biomedical Engineering, Marquette University,

Department of Biomedical Engineering, Marquette University, 
NOT THE PUBLISHED VERSION; this is the author's final, peer-reviewed manuscript. The published version may be accessed by following the link in the citation at the bottom of the page.

\author{
E. Gros \\ GE Healthcare, \\ Waukesha, WI \\ D. Okerlund \\ GE Healthcare, \\ Waukesha, WI \\ T.G. Schmidt \\ Department of Biomedical Engineering, Marquette University, \\ Milwaukee, WI
}

\begin{abstract}
:
Purpose: Reconstructing a low-motion cardiac phase is expected to improve coronary artery visualization in coronary computed tomography angiography (CCTA) exams. This study developed an automated algorithm for selecting the optimal cardiac phase for CCTA reconstruction. The algorithm uses prospectively gated, single-beat, multiphase data made possible by wide cone-beam imaging. The proposed algorithm differs from previous approaches because the optimal phase is identified based on vessel image quality (IQ) directly, compared to previous approaches that included motion estimation and interphase processing. Because there is no processing of interphase information, the algorithm can be applied to any sampling of image phases, making it suited for prospectively gated studies where only a subset of phases are available.
\end{abstract}

Methods: An automated algorithm was developed to select the optimal phase based on quantitative IQ metrics. For each reconstructed slice at each reconstructed phase, an image quality metric was calculated based on measures of circularity and edge strength of through-plane vessels. The image quality metric was aggregated across slices, while a metric of vessellocation consistency was used to ignore slices that did not contain throughplane vessels. The algorithm performance was evaluated using two observer studies. Fourteen single-beat cardiacCT exams (Revolution CT, GE Healthcare, Chalfont St. Giles, UK) reconstructed at 2\% intervals were evaluated for best systolic (1), diastolic (6), or systolic and diastolic phases (7) by three readers and the algorithm. Pairwise inter-reader and reader-algorithm agreement was evaluated using the mean absolute difference (MAD) and concordance correlation coefficient (CCC) between the reader and algorithm-selected phases. A reader-consensus best phase was determined and compared to the algorithm selected phase. In cases where the algorithm and consensus best 
phases differed by more than $2 \%$, IQ was scored by three readers using a five point Likert scale.

Results: There was no statistically significant difference between inter-reader and reader-algorithm agreement for either MAD or CCC metrics $(p>0.1)$. The algorithm phase was within $2 \%$ of the consensus phase in $15 / 21$ of cases. The average absolute difference between consensus and algorithm best phases was $2.29 \% \pm 2.47 \%$, with a maximum difference of $8 \%$. Average image quality scores for the algorithm chosen best phase were $4.01 \pm 0.65$ overall, $3.33 \pm 1.27$ for right coronary artery $(R C A), 4.50 \pm 0.35$ for left anterior descending (LAD) artery, and $4.50 \pm 0.35$ for left circumflex artery (LCX). Average image quality scores for the consensus best phase were 4.11 \pm 0.54 overall, $3.44 \pm 1.03$ for RCA, $4.39 \pm 0.39$ for LAD, and $4.50 \pm 0.18$ for LCX. There was no statistically significant difference $(p>0.1)$ between the image quality scores of the algorithm phase and the consensus phase.

Conclusions: The proposed algorithm was statistically equivalent to a reader in selecting an optimal cardiac phase for CCTA exams. When reader and algorithm phases differed by $>2 \%$, image quality as rated by blinded readers was statistically equivalent. By detecting the optimal phase for CCTA reconstruction, the proposed algorithm is expected to improve coronary artery visualization in CCTA exams.

Keywords: Heart, Vascular system, Medical image reconstruction, Computed tomography, Medical image contrast

\section{Introduction}

In 2004, coronary artery disease was the most expensive condition for hospitals to treat, costing over $\$ 44$ billion for 1.2 million patients. ${ }^{1}$ The gold-standard metric to determine the presence and severity of stenoses is $\mathrm{x}$-ray angiography. Noninvasive coronary computed tomography angiography (CCTA) exams are often used to exclude clinically significant coronary stenosis because of their high negative predictive value. ${ }^{2}$ Cardiac motion can blur the coronary arteries in the CCTA images, making it difficult for clinicians to perform an accurate diagnostic interpretation. Ideally, reconstruction will occur during the phase of the cardiac cycle with the least motion; however, this minimum motion phase varies from patient to patient and is related to the patient's heart rate. ${ }^{3,4}$ The best phase for reconstruction can be estimated based on the patient's heart rate, combined with a model of the cardiac cycle to determine the phase corresponding to end-systole or mid-diastole. However, there is high patient variability in the exact location of these states, which may result in the reconstruction of suboptimal images. ${ }^{4}$

Medical Physics, Vol 43, No. 1 (January 2016): pg. 324-335. DOI. This article is @ American Association of Physicists in Medicine and permission has been granted for this version to appear in e-Publications@Marquette. American Association of Physicists in Medicine does not grant permission for this article to be further copied/distributed or hosted elsewhere without the express permission from American Association of Physicists in Medicine. 
NOT THE PUBLISHED VERSION; this is the author's final, peer-reviewed manuscript. The published version may be accessed by following the link in the citation at the bottom of the page.

In current practice, multiple phases may be reviewed manually to select the volume with the best image quality (IQ). This process requires additional computation time to reconstruct each volume. As the use of computationally intensive iterative reconstruction techniques continues to grow, minimizing the number of reconstructed phases is essential. A manual best phase selection may also be timeconsuming for radiologists who must review multiple sets of images.

To improve workflow, fully automated algorithms to determine the lowest-motion cardiac phase have been developed ${ }^{5,6}$ and clinically implemented. ${ }^{7,8}$ The kymogram approach was proposed to calculate the motion of the center-of-mass of the heart from raw projection data. ${ }^{6}$ Since this approach does not require image reconstruction at multiple phases, it is computationally efficient. However, using a motion metric based on the heart center of mass may not be optimal for the coronary arteries. ${ }^{9}$ Other automated phase selection algorithms, including the clinically implemented algorithms, are based on estimating motion from multiphase data. ${ }^{7,8,10}$ For example, one approach uses the difference and/or correlation between lowresolution heart volumes at consecutive phases to estimate the motion of the heart. ${ }^{10} \mathrm{~A}$ different, clinically-available approach calculates the difference between voxels in neighboring phases in order to estimate a motion function. ${ }^{8}$ In a recently proposed algorithm, a deviation metric is calculated as the correlation coefficient between the segmented coronary artery volumes of neighboring phases. ${ }^{11}$ The low-motion phase is selected based on the estimated velocity, which is approximated from the deviation metric assuming linear motion and limited vessel deformation in the reconstructed image. The algorithm demonstrated an average phase agreement of 5\% between the proposed algorithm and the clinical algorithm, with comparable or better subjective image quality ratings for the selected phase. ${ }^{11}$ One limitation of this algorithm is that the coronary artery segmentation was not fully automated. As with previous algorithms, low-motion phases were selected using phase-to-phase processing, typically using $4 \mathrm{D}$ data reconstructed at $1 \%$ phase intervals. ${ }^{8,11}$

The objective of this study was to develop and evaluate an automated algorithm to select the best cardiac phase for CCTA reconstruction. The proposed algorithm differs from the previous approaches because the optimal phase is identified based on vessel

Medical Physics, Vol 43, No. 1 (January 2016): pg. 324-335. DOI. This article is @ American Association of Physicists in Medicine and permission has been granted for this version to appear in e-Publications@Marquette. American Association of Physicists in Medicine does not grant permission for this article to be further copied/distributed or hosted elsewhere without the express permission from American Association of Physicists in Medicine. 
image quality directly, compared to the previous approaches that included motion estimation and interphase processing. In the proposed algorithm, the coronary image quality metrics are calculated independently for each phase and the phase with the highest image quality is selected. Because there is no processing of interphase information, the algorithm can be applied to any sampling of image phases, making it suited for prospectively gated studies where only a subset of phases (typically end-sytolic and/or mid-diastolic phase range) are available. The algorithm is specifically designed and is the first to be applied to single-beat, wide cone-beam CT system, leveraging inherent multiphase data within the prospective gating window while avoiding the stitching of data from multiple heart beats.

\section{Materials and Methods}

This section describes the proposed algorithm for best phase selection as well as the phantom and observer studies used to evaluate algorithm performance.

\section{A. Algorithm for automated phase selection}

When vessels travel longitudinally through axial slices of the heart (i.e., through-plane vessels), the vessel cross sections are circular. Blurring due to motion causes the vessels to appear less circular with weaker edges. Based on these characteristics, the algorithm selects the lowest-motion phase by calculating an IQ metric that quantifies the circularity and edge strength of the vessels. Vessels depicted with low motion will have high circularity and edge strength, and thus high IQ scores.

A summary of the algorithm steps is shown in Fig. 1. CT images reconstructed from all phases of interest from the CT exam are input to the algorithm. The image quality is calculated independently for each phase; therefore, the algorithm is designed to find the best phase from any sampling of input phases. In each input 2D image, throughplane IQ is calculated for the right coronary artery (RCA), left anterior descending (LAD) artery, and the left circumflex artery (LCX). The IQ is calculated independently for each slice (2D image processing) so that the algorithm could potentially be applied to a subset of slices in

Medical Physics, Vol 43, No. 1 (January 2016): pg. 324-335. DOI. This article is (C American Association of Physicists in Medicine and permission has been granted for this version to appear in e-Publications@Marquette. American Association of Physicists in Medicine does not grant permission for this article to be further copied/distributed or hosted elsewhere without the express permission from American Association of Physicists in Medicine. 
order to reduce computational requirements. Next, slices without through-plane vessels are identified and excluded. IQ scores from slices that contain through-plane vessels are combined to determine a score for the RCA, LAD, and LCX at each phase. The vessel scores are then combined to calculate an overall through-plane score for each phase. These steps are described in detail in Secs. 2.A.1 and 2.A.2.

\section{A.1. Processing of 2D axial image slices}

The following steps are performed independently for each 2D axial image input to the algorithm, where each 2D image represents a specific slice at a specific phase.

\section{A.1.a. Segment cardiac region.}

The proposed algorithm does not require a full 3D dataset. Therefore, standard 3D cardiac segmentation algorithms cannot be used. A 2D segmentation algorithm for axial slices of the heart was developed and is described in detail in the Appendix. The segmentation algorithm takes a single axial slice as input and locates the cardiac region in that image based on the contour between the heart and lungs.

\section{A.1.b. Quantify IQ for each slice and phase.}

Several preprocessing steps are carried out to prepare each image for the IQ calculation. Once per slice, three thresholds are calculated: a soft tissue threshold, a contrast threshold, and a maximum value threshold. The patient-specific thresholds are calculated using the histogram of the segmented image divided into bins of $30 \mathrm{HU}$ width. The soft tissue threshold, representing the approximate value of the background tissue in the heart, is selected as the first peak in the segmented image histogram. The contrast threshold, representing the approximate value in the chambers of the heart, is selected as the second highest peak in the histogram. The maximum value threshold, representing the largest value in the image that does not include contrast pooling or calcification, is calculated as the highest histogram bin that contains at least $0.05 \%$ of the total image points. Next, a gamma transform $(Y=0.7)$ is applied to pixels above the maximum value threshold to attenuate high values in the

Medical Physics, Vol 43, No. 1 (January 2016): pg. 324-335. DOI. This article is @ American Association of Physicists in Medicine and permission has been granted for this version to appear in e-Publications@Marquette. American Association of Physicists in Medicine does not grant permission for this article to be further copied/distributed or hosted elsewhere without the express permission from American Association of Physicists in Medicine. 
image that can skew the output of the subsequent gradient and filtering operations.

A chamber removal mask, based on the gray-scale morphological open of each image (Fig. 2), is created to de-emphasize the chambers of the heart as well as contrast swirling. A circular structuring element with a radius of $10 \mathrm{~mm}$ was chosen to completely remove through-plane vessels during the erosion operation. Values from the opened image are scaled so that the range from the soft tissue threshold to contrast threshold in the open image is mapped to a range from 0 to 1 [Fig. 2(c)]. Contrast swirling can cause inconsistent values in the chamber that may appear as small structures during the opening operation. This is why the edges of the right atrium are still present in the mask in Fig. 2(c). To account for this, any values connected to a chamber that are greater than the maximum value threshold are marked as regions of contrast swirling. Regions of contrast swirling are dilated and given a value of zero in the mask [Fig. 2(d)]. The resulting mask [Fig. 2(e)] has zeros in areas representing heart chambers and ones in areas where the background is soft tissue.

A top hat transform is applied to the original image to focus on small, high-valued regions such as vessels. ${ }^{12}$ The circular structuring element described above for the morphological opening is also used for the top hat transform.

The product of an edge strength score and a circularity score determines the IQ for each through-plane vessel in each image. The edge strength score is also used by the algorithm to identify regions that could be through-plane vessels. The top hat image, chamber removal mask, and a matched filter are used to calculate the edge strength score, as illustrated in Fig. 3. In the first step of the edge strength score calculation, the gradient of the top hat transform is calculated using a Sobel filter and then multiplied by the chamber removal mask [Fig. 3(c)]. The chamber removal mask is applied after the gradient to remove strong gradients at the edges of the heart and heart chambers. Next, a matched filter is applied to the gradient image.

The matched filter (Fig. 4) is described in

Medical Physics, Vol 43, No. 1 (January 2016): pg. 324-335. DOI. This article is @ American Association of Physicists in Medicine and permission has been granted for this version to appear in e-Publications@Marquette. American Association of Physicists in Medicine does not grant permission for this article to be further copied/distributed or hosted elsewhere without the express permission from American Association of Physicists in Medicine. 


$$
M(\rho)=\left\{\begin{array}{cc}
\cos \left(\frac{\pi\left(\rho-R_{1}\right)}{2\left(R_{2}-R_{1}\right)}\right) & 0 \leq \rho<R_{2} \\
-\sin \left(\frac{\pi\left(\rho-R_{2}\right)}{\left(R_{3}-R_{2}\right)}\right) & R_{2} \leq \rho<R_{3} \\
0 & R_{3} \leq \rho
\end{array}\right.
$$

where $\rho$ is the radial distance from the center of the matched filter. R1 is the radius of maximum positive response, which was set to 1.25 $\mathrm{mm}$ to reflect the expected vessel radius of $0.75-1.5 \mathrm{~mm}$. Gradients outside this range are likely due to blurring and therefore elicit a weaker response from the filter. $R_{2}$ (set to $4 \mathrm{~mm}$ ) is the radius of the first zero crossing and represents the range of distances with positive filter response. $R_{3}$ (set to $7 \mathrm{~mm}$ ) is the total radial extent of the filter. The filter has a negative lobe between $R_{2}$ and $R_{3}$ (radii of 4-7 $\mathrm{mm}$ ) in order to reduce the response from larger structures. An alternative approach of using a difference of Gaussian (DoG) filter was investigated to replace the two-step process of the gradient operation followed by a matched filter. However, the DoG was found to be less effective at rejecting long, thin objects such as contrast swirling and was found to be more biased toward larger objects than the matched filter described in Eq. (1). At the conclusion of this step, the convolution of the matched filter with the top hat image gradient gives the edge strength score at each point in the image.

Next, candidate vessel points are identified in the edge strength score image. Pixels with the highest edge strength scores are likely to be vessels. However, the edge strength score can yield a high response to structures where only one dimension is near the expected vessel radius. Therefore, candidate points for each of the three main vessels (RCA, LAD, and LCX) with high edge strength scores are analyzed further to determine their circularity. For each image, a binary mask is created with pixels within the segmented cardiac region set equal to one. The centroid of the binary mask is considered as the center point that defines three regions of the heart. The right side contains the RCA, the left anterior quadrant contains the LAD, and the left posterior quadrant contains the LCX. The three highest valued 
regional maxima in each of the three regions are chosen as candidate vessel center points.

The circularity score, Eq. (2), is a measure of compactness that was previously proposed for binary images, where a value of one is the most compact and higher values are less compact, ${ }^{13}$

$$
\text { Compactness }=\frac{\text { Perimeter }^{2}}{4 \pi \text { Area }} \text {. }
$$

In the proposed algorithm, a $25 \times 25 \mathrm{~mm}$ ROI around each candidate point in the top hat image is considered. First, the center of the vessel is identified as the largest value in a small radius near the candidate point. Next, the ROI is thresholded into four levels based on a percentage of the vessel center value: $>50 \%,>40 \%,>30 \%$, and $>20 \%$. As the threshold is decreased, a larger portion of the vessel edges and any blurring due to motion is included. Therefore, these four images show the shape of the vessel and the magnitude of motion artifact. For each level, regions above the threshold are labeled with a connected-components algorithm using four-connectivity, and the region that contains the center of the vessel is selected. The compactness of each of these four binary regions is calculated and compiled into a measure of circularity using Eq. (3)

$$
\text { Circularity }=\frac{1}{\sum_{d=2}^{5} d} \sum_{d=2}^{5} d^{*}\left[2-\min \left(\text { Compactness }_{d}, 2\right)\right] \text {. }
$$

Compactness $d$ refers to the compactness of the selected region when the ROI is thresholded at $d * 10 \%$ of the center vessel value. Theoretically, the compactness is equal to one for perfect circles and is greater than one for less circular objects. In practice, compactness values less than one are possible due to the calculation of perimeter in the discretized image. Compactness values greater than two are poor circles. Therefore, the compactness values are transformed, as described in Eq. (3), so that values greater than two (poor circles) are 
set to zero and objects with greater circularity have higher values. An increased weight is placed on higher thresholds because distortion seen at lower thresholds is lower in magnitude and, therefore, should have a lower effect on the circularity metric. The circularity metric calculation is depicted in Fig. 5.

After edge and circularity scores are calculated, they are multiplied together for each candidate point to determine the final through-plane IQ metric. The candidate point from each vessel region with the highest through-plane IQ score is chosen to represent through-plane IQ for the vessel in that slice and phase. The throughplane IQ calculation is executed for a particular slice at all phases then repeated for each input slice.

\section{A.2. Evaluating IQ scores across slices and phases}

\section{A.2.a. Select slices with through-plane vessels.}

In order to compare phases across the heart volume, the IQ metrics must be aggregated across relevant slices. This step of the algorithm locates slices that contain through-plane vessels, allowing slices without through-plane vessels to be ignored in the aggregate IQ calculation for each phase. The locations with high IQ for the RCA, LAD, and LCX at each slice and phase (as output by the previous step) are used to locate the relevant slices by creating vessel maps.

Vessel maps are created at each phase to identify the location of the RCA, LAD, and LCX. Consider an ideal through-plane vessel that is perpendicular to the axial plane. In slices that contain the vessel, high IQ points will be in the same location in the axial plane. In slices without through-plane vessels, high IQ points will be at random locations because the IQ score is based on noise. Therefore, throughplane vessels can be identified by a set of slices with high IQ points at the same axial location. In reality, the axial location is allowed to vary so that the vessel is traveling at less than a $45^{\circ}$ angle from the z-axis. Vessels that deviate by more than $45^{\circ}$ from the $z$-axis would not appear as circles in an axial slice and would not meet the assumptions of the calculated IQ metrics. Vessel maps are found by recursively searching for points with axial locations within $45^{\circ}$ of the current point. The recursion stops when two slices in a row cannot find a nearby

Medical Physics, Vol 43, No. 1 (January 2016): pg. 324-335. DOI. This article is (C) American Association of Physicists in Medicine and permission has been granted for this version to appear in e-Publications@Marquette. American Association of Physicists in Medicine does not grant permission for this article to be further copied/distributed or hosted elsewhere without the express permission from American Association of Physicists in Medicine. 
point. This produces list of potential vessels for a particular phase. Any potential vessels that span less than $10 \mathrm{~mm}$ in the $z$-direction are discarded. This process is repeated for all vessels at all phases.

Vessel maps can be used to determine which slices contain each through-plane vessel. The number of phases that found each vessel (RCA, LAD, and LCX) at each slice is determined based on the vessel maps. Ideally, all phases will find through-plane vessels at the exact same slices. However, phases with very low image quality are unlikely to correctly identify through-plane slices. Therefore, slices are selected as containing relevant data when at least $25 \%$ of the total number phases were identified as containing through-plane vessels.

\section{A.2.b. Select best phase.}

This step calculates an IQ score for each phase, by aggregating across slices. At this point in the algorithm, IQ has been calculated for each cardiac phase in all slices. The slices that contain through-plane vessels for each vessel have been identified. Next, the IQ values are summed across all slices that contain through-plane vessels. This results in an aggregate vessel IQ score at each phase for the RCA, $L A D$, and LCX. The scores for the LAD and LCX are added to give an overall left side score. The best phase for each side is the phase with the largest IQ score on that side. The results from the right and left sides are normalized by their mean and summed to find the overall IQ.

\section{B. Phantom study to evaluate circularity image quality metric}

A dynamic phantom study was performed to validate that high values of the circularity metric [Eqs. (2) and (3)] represent phases with low vessel motion. A 2-mm-diameter tube was filled with iodinebased contrast and attached to the outside of a myocardial phantom. The phantom was dynamically moved to simulate the typical motion profile of the heart. The phantom was imaged on a clinical scanner (Revolution CT, GE Healthcare, Chalfont St. Giles, UK) with $0.28 \mathrm{~s}$ rotation. Images were reconstructed at phases in the simulated cardiac cycle corresponding to average velocities of $10,17,33,53$, and $65 \mathrm{~mm} / \mathrm{s}$. The vessel location was manually identified on a subset

Medical Physics, Vol 43, No. 1 (January 2016): pg. 324-335. DOI. This article is (C) American Association of Physicists in Medicine and permission has been granted for this version to appear in e-Publications@Marquette. American Association of Physicists in Medicine does not grant permission for this article to be further copied/distributed or hosted elsewhere without the express permission from American Association of Physicists in Medicine. 
of slices. The circularity metric, as described in Eqs. (2) and (3), was calculated for each motion phases and for a static scan of the phantom.

\section{C. Evaluation using clinical CCTA datasets}

The proposed algorithm was evaluated using 12 previously acquired, anonymized, single-beat datasets (Revolution CT, GE Healthcare, Chalfont St. Giles, UK). Table I summarizes the characteristics of the acquired datasets. Three datasets contained one or more stents, one dataset contained a triple-vessel bypass graft, three datasets were identified as containing tortuous or atypical RCA orientations, and eight datasets contained visible plaques in the coronary arteries. The axial, single-beat acquisitions were performed with 0.28 s rotation and with tube voltages of 80 (1 dataset), 100 (1 dataset), 120 (11 datasets), and $140 \mathrm{kV}$ (1 dataset). The tube current was selected for each patient based on the automated exposure control settings, with effective dose, estimated from the dose-length product, ${ }^{14}$ listed in Table $\mathrm{I}$. The contrast timing was based on a test bolus.

All scans were prospectively triggered acquisitions with retrospectively gated reconstructions. The appropriate triggered exposure window was selected prior to each scan based on heart rate and heart rate variability. The selected phase range is automatically padded during acquisition so that the selected phase range has the expected noise levels. Typically, tube current is turned on during endsystole and/or mid-diastole, as these are the typical periods of low motion. ${ }^{3,15}$ The duration of diastole decreases with increasing heart rate, while systole is less dependent on heart rate. ${ }^{16-18}$ Therefore, the end-systolic period of low motion was typically selected for high heart rates or cases with high heart rate variability. Six cases were acquired at a diastolic phase range, one case was an end-systolic phase range only, and the remaining seven cases acquired both a systolic and diastolic phase range. Three of the scans were CT perfusion studies that were retrospectively processed as CCTA exams. The perfusion scans represent the high dose outliers in Table I, as they were acquired with full phase ranges and without tube current modulation, 
which differs from the typical CCTA protocol ( $<25 \%$ of cardiac cycle with tube current modulation).

A $200 \times 200 \times 160 \mathrm{~mm}$ CT volume was reconstructed with the standard reconstruction kernel, slice thickness of $2.5 \mathrm{~mm}$, and matrix size $512 \times 512$ for phases at intervals of $2 \%$ of the $\mathrm{R}-\mathrm{R}$ interval within the prospectively gated phase range. At this $2 \%$ interval, the average number of reconstructed phases was eight for the systolic-gated exam, 15 phases for the diastolic-gated exams, and 38 reconstructed phases for exams gated for both systole and diastole. To perform a preliminary investigation of the effects of reconstruction kernel on the algorithm performance, four exams with stents and/or plaques were additionally reconstructed using the detail and edge reconstruction kernels.

\section{C.1. Observer best phase study}

An observer study was performed to compare the best phases selected by the proposed algorithm to the best phases selected by trained readers. Three readers identified the best systolic and diastolic phases for CCTA reconstruction for each dataset. Next, the readers worked together to identify a consensus best phase for each exam, which was used in the subsequent image quality observer study described in Sec. 2.C.2. Because selecting the best phase is a subjective observer task, some discrepancies are expected between the readers. Two pairwise metrics were used to quantify the agreement between two readers and to quantify the agreement between the algorithm and a reader: mean absolute difference (MAD) and concordance correlation coefficient (CCC). ${ }^{19}$ The MAD is the absolute value of the difference in the selected best phase. The CCC is a modified version of the Pearson correlation coefficient that fixes the best fit line at $45^{\circ}$ from the origin. If the results of different measurement techniques are plotted on each axis, the metric will represent the reproducibility between techniques. In this study, the best phase selected by a reader was plotted against the best phase selected by a different reader or the best phase selected by the algorithm.

Both MAD and CCC metrics were calculated for every possible pairwise combination of the three readers and the algorithm. This

Medical Physics, Vol 43, No. 1 (January 2016): pg. 324-335. DOI. This article is (C) American Association of Physicists in Medicine and permission has been granted for this version to appear in e-Publications@Marquette. American Association of Physicists in Medicine does not grant permission for this article to be further copied/distributed or hosted elsewhere without the express permission from American Association of Physicists in Medicine. 
provided three sets of reader-algorithm agreement metrics and three sets of inter-reader agreement metrics for each dataset. If the algorithm is as effective as a reader, there will be no difference between reader-algorithm and inter-reader metrics. A statistical analysis was performed to test the hypothesis that the agreement between the readers was equivalent to the agreement between the readers and the algorithm. To test this hypothesis, the difference between each inter-reader and reader-algorithm agreement metric was calculated to produce a population of nine differences for each dataset and for each of the CCC and MAD metrics. A bootstrapping analysis with 10000 resampling iterations estimated the test statistic of the mean difference between inter-reader and reader-algorithm metric values. The $95 \%$ confidence interval was analyzed to determine if the reader-algorithm pairwise agreement metrics were statistically significantly different than the inter-reader pairwise metrics.

\section{C.2. Observer image quality study}

A second observer study was performed to evaluate image quality in cases where the reader consensus best phase and the algorithm best phase did not agree. In exams where the consensus reader best phase and the algorithm best phase differed by more than $2 \%$, three trained readers evaluated image quality on a five point Likert scale for the RCA, LAD, LCX, and overall IQ, where 1 indicated an inevaluable vessel, 2 indicated considerable motion artifact, 3 indicated moderate motion artifact, 4 indicated minor motion artifact, and 5 indicated no apparent motion artifact. The consensus and algorithm chosen phases were presented in a blinded, random order, and readers were blinded to the phase of each volume. A statistical analysis tested the hypothesis that the image quality scores were statistically equivalent for the consensus and algorithm-selected phases. The mean difference between IQ scores for algorithm and consensus best phases was the test statistic estimated by a bootstrapping analysis of the observer scores (10 000 iterations). The $95 \%$ confidence interval was analyzed to determine if the algorithm best phase IQ was statistically significantly different than the consensus best phase IQ.

Medical Physics, Vol 43, No. 1 (January 2016): pg. 324-335. DOI. This article is @ American Association of Physicists in Medicine and permission has been granted for this version to appear in e-Publications@Marquette. American Association of Physicists in Medicine does not grant permission for this article to be further copied/distributed or hosted elsewhere without the express permission from American Association of Physicists in Medicine. 
NOT THE PUBLISHED VERSION; this is the author's final, peer-reviewed manuscript. The published version may be accessed by following the link in the citation at the bottom of the page.

\section{Results}

Figure 6 compares axial images at the "standard" end-systolic phase of $44 \%$ and the algorithm selected best phase of $40 \%$ for one case. Figure 6 also plots the overall vessel IQ score calculated by the algorithm for this exam, demonstrating the peak at $40 \%$ and the change in IQ over a narrow range of phases. Figure 7 displays images from the same case reformatted to visualize the length of the RCA vessel. Motion artifacts can be seen when the suboptimal end-systolic phase of $44 \%$ is reconstructed, despite the gantry rotation time of $0.28 \mathrm{~s}$. The image reconstructed at the algorithm-selected best phase demonstrates higher contrast and sharper vessel edges, suggesting reduced motion artifacts at a $4 \%$ phase difference. The algorithmselected phase did not change with reconstruction kernel for any of the four cases that were tested with varying kernels.

\section{A. Phantom study}

Figure 8 displays images of the phantom vessels for velocities of $0,10,17,33,53$, and $65 \mathrm{~mm} / \mathrm{s}$. The circularity score is also displayed for each phase. The results demonstrate that the circularity score increased with decreasing vessel velocity.

\section{B. Observer best phase study}

The inter-reader and reader-algorithm agreement are plotted in Fig. 9, demonstrating the variation between readers, the algorithm, as well as the variability across patients. The data in Fig. 9 are clustered around $42 \%$ and $75 \%$ for systolic and diastolic best phases, respectively.

The average inter-reader MAD was 2.60 compared to a readeralgorithm MAD of 2.57. The average inter-reader and reader algorithm CCC was 0.93 . Bootstrapping results showed no statistically significant difference in inter-reader and reader-algorithm CCC $(p=0.35)$ or MAD $(p=0.88)$ metrics, indicating that the algorithm was statistically equivalent to a reader.

Medical Physics, Vol 43, No. 1 (January 2016): pg. 324-335. DOI. This article is C American Association of Physicists in Medicine and permission has been granted for this version to appear in e-Publications@Marquette. American Association of Physicists in Medicine does not grant permission for this article to be further copied/distributed or hosted elsewhere without the express permission from American Association of Physicists in Medicine. 
NOT THE PUBLISHED VERSION; this is the author's final, peer-reviewed manuscript. The published version may be accessed by following the link in the citation at the bottom of the page.

The average systolic best phase was $42.6 \% \pm 3.2 \%$ for reader consensus and $41.9 \% \pm 3.4 \%$ for the algorithm. The average diastolic best phase was $75.8 \% \pm 2.8 \%$ for reader consensus and $77.3 \% \pm$ $2.7 \%$ for the algorithm. The histogram of the absolute phase difference between reader consensus and algorithm phases is shown in Fig. 10. Algorithm and consensus best phases differed by $0.8 \% \pm$ $1.0 \%$ for systole and $3.4 \% \pm 2.8 \%$ for diastole. The algorithm best phase was within $2 \%$ of the consensus best phase in $15 / 21$ of cases ( $8 / 8$ systole, $7 / 13$ diastole). The average absolute difference between consensus and algorithm best phases was $2.29 \% \pm 2.47 \%$.

\section{C. Observer image quality study}

Figure 11 compares the subjective image quality score for reader consensus and algorithm-selected best phases, for cases where the reader and algorithm selected phases differed by more than $2 \%$. Average image quality for the algorithm chosen best phase was $4.01 \pm$ 0.65 overall, $3.33 \pm 1.27$ for RCA, $4.50 \pm 0.35$ for LAD, and $4.50 \pm$ 0.35 for LCX. Average image quality for the consensus best phase was $4.11 \pm 0.54$ overall, $3.44 \pm 1.03$ for RCA, $4.39 \pm 0.39$ for LAD, and $4.50 \pm 0.18$ for LCX. For both the algorithm and consensus best phases, the RCA IQ was lower than the LAD or LCX IQ, likely due to higher average velocities in the right coronary arteries. ${ }^{3}$ Statistical analysis results showed no statistically significant difference between consensus and algorithm IQ for overall IQ or IQ of the RCA, LAD, or LCX. The $95 \%$ confidence interval of the mean difference in overall IQ score between algorithm and consensus phases was -0.28 to 0.28 with a mean value of -0.06 , indicating that there was no statistically significant difference in image quality between reader and algorithm chosen phases $(p=0.65)$.

Figure 12 displays images from the case where the algorithm and consensus best phase differed by the largest phase difference of $8 \%$. Images are displayed from the consensus phase of $72 \%$ and the algorithm phase of $80 \%$ for two slice locations. In the superior slice [Figs. 12(a) and 12(b)], the consensus phase demonstrates more motion artifacts for the RCA than the algorithm-selected phase. The opposite is true for the inferior slice [Figs. 12(c) and 12(d)], where the algorithm-selected phase contains more motion artifacts. Figure 12(e)

Medical Physics, Vol 43, No. 1 (January 2016): pg. 324-335. DOI. This article is @ American Association of Physicists in Medicine and permission has been granted for this version to appear in e-Publications@Marquette. American Association of Physicists in Medicine does not grant permission for this article to be further copied/distributed or hosted elsewhere without the express permission from American Association of Physicists in Medicine. 
compares the observer image quality score for this exam. The average overall and LCX IQ scores were 0.33 points higher for the consensus phase than the algorithm-selected phase, while the consensus and algorithm scores demonstrated the same range of values for the three individual vessels. The 0.33 point improvement in the overall IQ score was the highest improvement value calculated for the consensus phase across all exams. The highest improvement of the algorithm-selected phase compared to the consensus was 0.67 points.

\section{D. Discussion}

The observer best phase study compared the inter-reader variation to the reader-algorithm variation. Analysis demonstrated no statistically significant difference in inter-reader and reader-algorithm values for CCC and MAD, suggesting that the algorithm was statistically equivalent to a reader in selecting the best phase. In Fig. 9, both inter-reader and reader-algorithm scatter plots show clusters around end-systolic and mid-diastolic phases, which are the expected regions of low motion. However, Fig. 9 also demonstrates the variation of best phase across patients within the end-systole and mid-diastole clusters.

The reader consensus best phase agreed closely with the algorithm best phase with a mean difference of $2.29 \% \pm 2.47 \%$. This is an improvement on previous automated retrospective best phase algorithms in the literature. The kymogram algorithm demonstrated a mean difference of $12.5 \% .{ }^{9}$ A previous study found that one version of a motion map algorithm had a mean difference of $6.1 \% \pm 5.9 \%$ for systolic phases and $5.0 \% \pm 4.7 \%$ for diastolic phases. ${ }^{8}$ The phase difference was over $5 \%$ in $46 \%$ of systolic and $36 \%$ of diastolic exams compared to a difference of over $2 \%$ in $29 \%$ of exams in this study. In contrast, a different study found that, using a motion map algorithm, the best phase would be within $6.8 \%$ of the consensus best phase $95 \%$ of the time. ${ }^{5}$ However, this study allowed the algorithm to pick up to four phases and observers to pick up to three phases and only the nearest algorithm and observer phases were considered.

The best phase study in this work (Secs. 2.C.1 and 3.B) quantified results based on a phase difference between algorithm and reader best phases. The phase difference is not always proportional to

Medical Physics, Vol 43, No. 1 (January 2016): pg. 324-335. DOI. This article is (C) American Association of Physicists in Medicine and permission has been granted for this version to appear in e-Publications@Marquette. American Association of Physicists in Medicine does not grant permission for this article to be further copied/distributed or hosted elsewhere without the express permission from American Association of Physicists in Medicine. 
the IQ difference. A 4\% phase difference can have a considerable effect on image quality, while two phases $6 \%$ apart can have similar image quality. The observer IQ study (Secs. 2.C.2 and 3.C) was conducted to determine whether, when the algorithm and consensus phase differed by $>2 \%$, both phases had equivalent IQ. There was no exam where two readers agreed that the overall IQ of the algorithm best phase was worse than the consensus best phase. However, in one exam, two out of three observers gave the algorithm best phase a better score than the consensus best phase. This suggests that there was no exam where the algorithm chosen best phase was perceived as worse than the consensus best phase. The IQ study found no statistically significant difference in subjective observer IQ between algorithm and consensus phases when the phase difference was $>2 \%$ for overall IQ or IQ of the RCA, LAD, or LCX. In the previous studies that evaluated image quality, one found a statistically significant difference between algorithm and consensus IQ, while another study did not find a statistically significant difference. ${ }^{20}$

In the current study, the difference between algorithm and consensus best phases was less than or equal to $2 \%$ for all systolic phases. This is likely because the low-motion period in end-systole is typically very short. Diastasis tends to be longer, especially at low heart rates. The two exams with the lowest heart rates (60 bpm) had a phase difference $>2 \%$ for the best diastolic phase. Because of the longer low-motion interval, there is a wider window of phases that yield equivalent low-motion results.

By processing each image phase independently, the algorithm is designed to select the best phase from the phases that are input to the algorithm. In this study, images were reconstructed at a phase interval $2 \%$ within the prospective gating window. If the phase sampling interval was increased, the calculation of the IQ score for each input phase would remain the same and algorithm would select the best phase from the input images. Figures 6 and 7 demonstrate a large change in RCA image quality over a $4 \%$ phase difference, as well as the variation of the overall IQ score at $2 \%$ phase intervals. This suggests that a reconstructed phase interval of $2 \%-4 \%$ may be preferable for ensuring that the true best phase is input into the algorithm for processing. In this study, the minimum prospective gating window was $\pm 8 \%$ (two datasets, including the one shown in

Medical Physics, Vol 43, No. 1 (January 2016): pg. 324-335. DOI. This article is (C) American Association of Physicists in Medicine and permission has been granted for this version to appear in e-Publications@Marquette. American Association of Physicists in Medicine does not grant permission for this article to be further copied/distributed or hosted elsewhere without the express permission from American Association of Physicists in Medicine. 
Figs. 6 and 7). As seen in Figs. 6 and 7, the algorithm selected a phase with higher image quality than a neighboring phase, even within the relatively narrow gating window. Further reduction of the prospective gating window is desirable for dose reduction. Because the algorithm processes each phase independently, the algorithm is unaffected by the range of input phases, and will select the input phase with the highest IQ score. Overall, in order for the algorithm to find the global best phase, images reconstructed at that phase must be input to the algorithm. Therefore, the algorithm relies on proper selection of the prospective gating window including proper modulation of the tube current to ensure adequate noise statistics across the gating window. When applied to a clinically relevant end-systolic or mid-diastolic phase range, we have found the processing time of an optimized software implementation of the algorithm (including the reconstruction of the determined target phase) to be less than that of a commonly prescribed three-phase CCTA reconstruction.

There were several limitations in this study. A gold-standard metric of IQ is not available for coronary imaging. Therefore, IQ was subjectively assessed by blinded readers. The intrareader variability in IQ scores was reduced by using three readers. When selecting the best phase, readers can exhibit a bias toward typical end-systolic and middiastolic locations. This bias was eliminated in the IQ study by blinding the readers to the phase of the volume. A limited study of four cases suggested that reconstruction kernel and the associated increased noise from sharper filters did not affect algorithm performance. However, additional studies are required to further study the effects of noise. Also, the algorithm was evaluated only with adult datasets. The algorithm may not be directly applicable to pediatric datasets, as vessel size and orientation may differ from adult scans. Unlike motionbased phase selection algorithms, the proposed algorithm optimizes the image quality of the coronary arteries directly. Therefore, the proposed algorithm may not identify the lowest motion phase for other cardiac structures.

Images reconstructed at the algorithm-selected best phase could be subsequently processed with an intercycle motion correction algorithm to remove residual motion artifacts. ${ }^{21}$ Future work is planned to investigate combining the phase-selection algorithm with motion correction. The current algorithm is designed for single-beat, wide of Physicists in Medicine does not grant permission for this article to be further copied/distributed or hosted elsewhere without the express permission from American Association of Physicists in Medicine. 
cone-beam exams. The algorithm could be generalized for multibeat cases, which poses unique challenges because of slab misregistration artifacts and varying IQ between slabs.

\section{Conclusions}

An automated algorithm was developed to select the lowest motion phase for CCTA reconstruction. The results of the observer study demonstrated that the algorithm was statistically equivalent to a trained reader. In cases where the algorithm-selected and consensus best phases differed by $>2 \%$, there was no statistically significant difference in image quality scores for the overall exam or for the RCA, LAD, or LCX vessels.

\section{Acknowledgment}

This study was funded by a research grant from GE Healthcare.

\section{References}

1 A. S. Go, D. Mozaffarian, V. L. Roger, E. J. Benjamin, J. D. Berry, M. J. Blaha, S. Dai, E. S. Ford, C. S. Fox, S. Franco, H. J. Fullerton, C. Gillespie, S. M. Hailpern, J. A. Heit, V. J. Howard, M. D. Huffman, S. E. Judd, B. M. Kissela, S. J. Kittner, D. T. Lackland, J. H. Lichtman, L. D. Lisabeth, R. H. Mackey, D. J. Magid, G. M. Marcus, A. Marelli, D. B. Matchar, D. K. McGuire, E. R. Mohler, C. S. Moy, M. E. Mussolino, R. W. Neumar, G. Nichol, D. K. Pandey, N. P. Paynter, M. J. Reeves, P. D. Sorlie, J. Stein, A. Towfighi, T. N. Turan, S. S. Virani, N. D. Wong, D. Woo, and M. B. Turner, "AHA statistical update heart disease and stroke statistics -2014 update a report from the American Heart Association," Circulation 129(3), e28-e292 (2014).http://dx.doi.org/10.1161/01.cir.0000441139.02102.80

2 U. Hoffmann, M. Ferencik, R. C. Cury, and A. J. Pena, "Coronary CT angiography," J. Nucl. Med. 47(5), 797-806 (2006).

3 M. Vembar, M. J. Garcia, D. J. Heuscher, R. Haberl, D. Matthews, G. E. Bohme, and N. L. Greenberg, "A dynamic approach to identifying desired physiological phases for cardiac imaging using multislice spiral CT," Med. Phys. 30(7), 1683 (2003).http://dx.doi.org/10.1118/1.1582812

4 T. Ota, M. Tsuyuki, M. Okumura, T. Sano, T. Kondo, and S. Takase, "Evaluation of exposure dose reduction in multislice CT coronary

Medical Physics, Vol 43, No. 1 (January 2016): pg. 324-335. DOI. This article is (C) American Association of Physicists in Medicine and permission has been granted for this version to appear in e-Publications@Marquette. American Association of Physicists in Medicine does not grant permission for this article to be further copied/distributed or hosted elsewhere without the express permission from American Association of Physicists in Medicine. 
NOT THE PUBLISHED VERSION; this is the author's final, peer-reviewed manuscript. The published version may be accessed by following the link in the citation at the bottom of the page.

angiography (MS-CTA) with prospective ECG-gated helical scan," Proc. SPIE 6913, 69134S-1-69134S-10 (2008).http://dx.doi.org/10.1117/12.771099

5 M. H. K. Hoffmann, J. Lessick, R. Manzke, F. T. Schmid, E. Gershin, D. T. Boll, S. Rispler, A. J. Aschoff, and M. Grass, "Automatic determination of minimal cardiac motion phases for computed tomography imaging: Initial experience," Eur. Radiol. 16(2), 365-373 (2006).http://dx.doi.org/10.1007/s00330-005-2849-z

6 M. Kachelrieß, D.-A. Sennst, W. Maxlmoser, and W. A. Kalender, "Kymogram detection and kymogram-correlated image reconstruction from subsecond spiral computed tomography scans of the heart," Med. Phys. 29(7), 1489 (2002).http://dx.doi.org/10.1118/1.1487861

7 R. M. S. Joemai, J. Geleijns, W. J. H. Veldkamp, A. de Roos, and L. J. M. Kroft, "Automated cardiac phase selection with 64-MDCT coronary angiography," AJR, Am. J. Roentgenol. 191(6), 1690-1697 (2008).http://dx.doi.org/10.2214/AJR.08.1039

8 H. Seifarth, M. Puesken, S. Wienbeck, D. Maintz, R. Fischbach, W. Heindel, and $\mathrm{K}$. U. Juergens, "Automatic selection of optimal systolic and diastolic reconstruction windows for dual-source CT coronary angiography," Eur. Radiol. 19(7), 1645-1652 (2009).http://dx.doi.org/10.1007/s00330-009-1329-2

9 D. Ertel, M. Kachelriess, T. Pflederer, S. Achenbach, R. M. Lapp, M. Nagel, and W. A. Kalender, "Raw data-based detection of the optimal reconstruction phase in ECG-gated cardiac image reconstruction," Med. Image Comput. Comput.-Assist. Intervention 9, 348-355 (2006).http://dx.doi.org/10.1007/11866763_43

10 R. Manzke, T. Köhler, T. Nielsen, D. Hawkes, and M. Grass, "Automatic phase determination for retrospectively gated cardiac CT," Med. Phys. 31(12), 3345 (2004).http://dx.doi.org/10.1118/1.1791351

11 C. A. Wick, J. H. McClellan, C. D. Arepalli, W. F. Auffermann, T. S. Henry, F. Khosa, A. M. Coy, and S. Tridandapani, "Characterization of cardiac quiescence from retrospective cardiac computed tomography using a correlation-based phase-to-phase deviation measure," Med. Phys. 42(2), 983-993 (2015).http://dx.doi.org/10.1118/1.4906246

12 R. Gonzalez and R. Woods, Digital Image Processing, 3rd ed. (Prentice Hall, Upper Saddle River, NJ, 2008).

13 L. O-Gorman, M. Sammon, and M. Seul, Practical Algorithms for Image Analysis (Cambridge University Press, Cambridge, 2008).

14 K. A. Jessen, P. C. Shrimpton, J. Geleijns, W. Panzer, and G. Tosi, "Dosimetry for optimisation of patient protection in computed tomography," Appl. Radiat. Isot. 50(1), 165-172 (1999).http://dx.doi.org/10.1016/S0969-8043(98)00024-4

Medical Physics, Vol 43, No. 1 (January 2016): pg. 324-335. DOI. This article is (C) American Association of Physicists in Medicine and permission has been granted for this version to appear in e-Publications@Marquette. American Association of Physicists in Medicine does not grant permission for this article to be further copied/distributed or hosted elsewhere without the express permission from American Association of Physicists in Medicine. 
15 S. Achenbach, D. Ropers, J. Holle, G. Muschiol, W. G. Daniel, and W. Moshage, "In-plane coronary arterial motion velocity: Measurement with electron-beam CT," Radiology 216(2), 457-463 (2000).http://dx.doi.org/10.1148/radiology.216.2.r00au19457

16 C. Herzog, N. Abolmaali, J. O. Balzer, S. Baunach, H. Ackermann, S. Dogan, M. B. Britten, and T. J. Vogl, "Heart-rate-adapted image reconstruction in multidetector-row cardiac $\mathrm{CT}$ : Influence of physiological and technical prerequisite on image quality," Eur. Radiol. 12(11), 2670-2678 (2002).http://dx.doi.org/10.1007/s00330002-1553-5

17 C. Herzog, M. Arning-Erb, S. Zangos, K. Eichler, R. Hammerstingl, S. Dogan, H. Ackermann, and T. J. Vogl, "Multi-detector row CT coronary angiography: Influence of reconstruction technique and heart rate on image quality," Radiology 238(1), 75-86 (2006).http://dx.doi.org/10.1148/radiol.2381041595

18 G. Sun, M. Li, L. Li, G. Li, H. Zhang, and Z. Peng, "Optimal systolic and diastolic reconstruction windows for coronary CT angiography using 320-detector rows dynamic volume CT," Clin. Radiol. 66(7), 614-620 (2011).http://dx.doi.org/10.1016/j.crad.2011.02.007

19 L. I. Lin, "A concordance correlation coefficient to evaluate reproducibility," Biometrics 45(1), 255-268 (1989).http://dx.doi.org/10.2307/2532051

20 B. Ruzsics, M. Gebregziabher, H. Lee, R. L. Brothers, T. Allmendinger, S. Vogt, P. Costello, and U. J. Schoepf, "Coronary CT angiography: Automatic cardiac-phase selection for image reconstruction," Eur. Radiol. 19(8), 1906-1913 (2009).http://dx.doi.org/10.1007/s00330009-1368-8

21 J. Leipsic, T. M. Labounty, C. J. Hague, G. B. J. Mancini, J. M. O’Brien, D. A. Wood, C. M. Taylor, R. C. Cury, J. P. Earls, B. G. Heilbron, A. M. Ajlan, G. Feuchtner, and J. K. Min, "Effect of a novel vendor-specific motion-correction algorithm on image quality and diagnostic accuracy in persons undergoing coronary CT angiography without rate-control medications," J. Cardiovasc. Comput. Tomogr. 6(3), 164-171 (2012).http://dx.doi.org/10.1016/j.jcct.2012.04.004

22 P. Soille, "Generalized geodesy via geodesic time," Pattern Recognit. Lett. 15, 1235-1240 (1994).http://dx.doi.org/10.1016/01678655(94)90113-9

23 P. Danielsson, "Euclidean distance mapping," Comput. Graphics Image Process. 14, 227-248 (1980).http://dx.doi.org/10.1016/0146$664 \times(80) 90054-4$ 


\section{Segment cardiac region}

\section{Quantify IQ for each slice and phase}

\section{Select slices with through-plane vessels}

\section{Select best phase}

FIG. 1. Overview of the steps to calculate image quality in through-plane vessels at each cardiac phase in a CCTA exam.

Medical Physics, Vol 43, No. 1 (January 2016): pg. 324-335. DOI. This article is (C) American Association of Physicists in Medicine and permission has been granted for this version to appear in e-Publications@Marquette. American Association of Physicists in Medicine does not grant permission for this article to be further copied/distributed or hosted elsewhere without the express permission from American Association of Physicists in Medicine. 
NOT THE PUBLISHED VERSION; this is the author's final, peer-reviewed manuscript. The published version may be accessed by following the link in the citation at the bottom of the page.
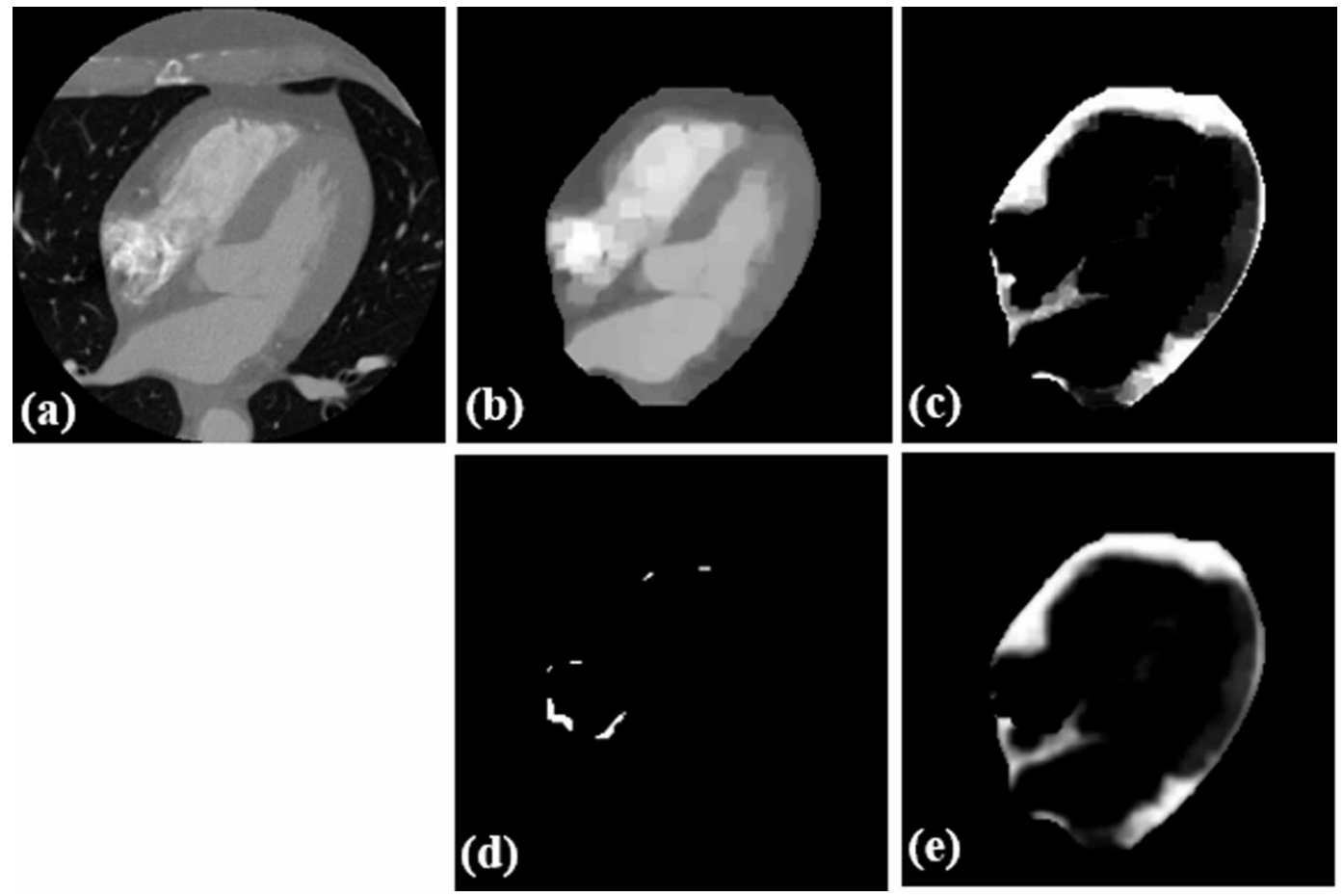

FIG. 2. Steps in chamber removal mask creation: (a) original image, (b) gray-scale morphological open, (c) initial mask, (d) points marked as contrast swirling, (e) final chamber removal mask.

Medical Physics, Vol 43, No. 1 (January 2016): pg. 324-335. DOI. This article is (C) American Association of Physicists in Medicine and permission has been granted for this version to appear in e-Publications@Marquette. American Association of Physicists in Medicine does not grant permission for this article to be further copied/distributed or hosted elsewhere without the express permission from American Association of Physicists in Medicine. 
(a)
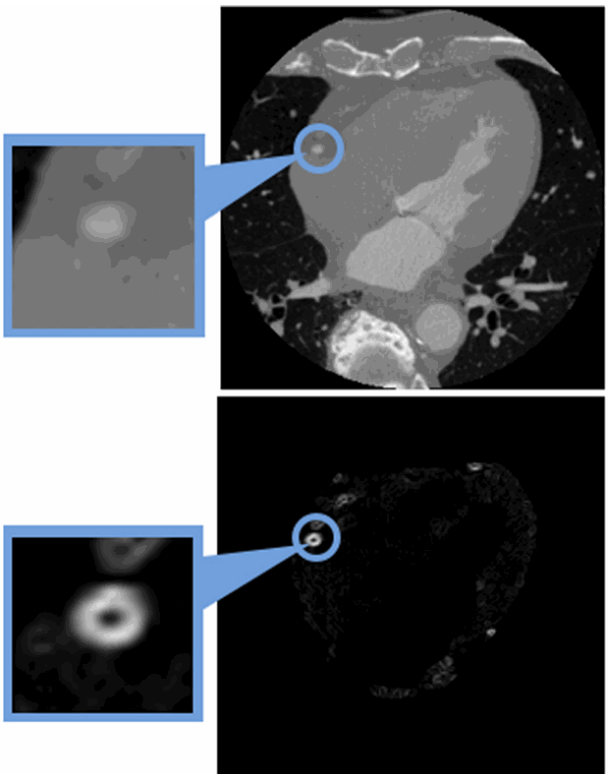

(b)

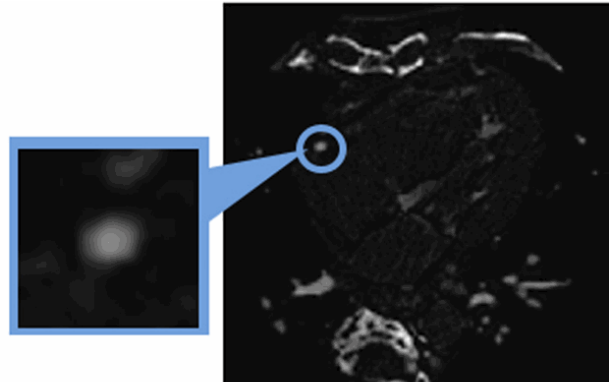

(d)
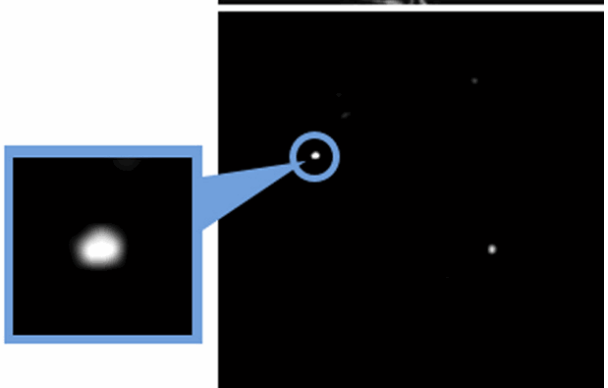

FIG. 3. Steps in edge score calculation: (a) original image, (b) top hat transform, (c) top hat transform gradient multiplied by the chamber removal mask, (d) final edge score after applying the matched filter.
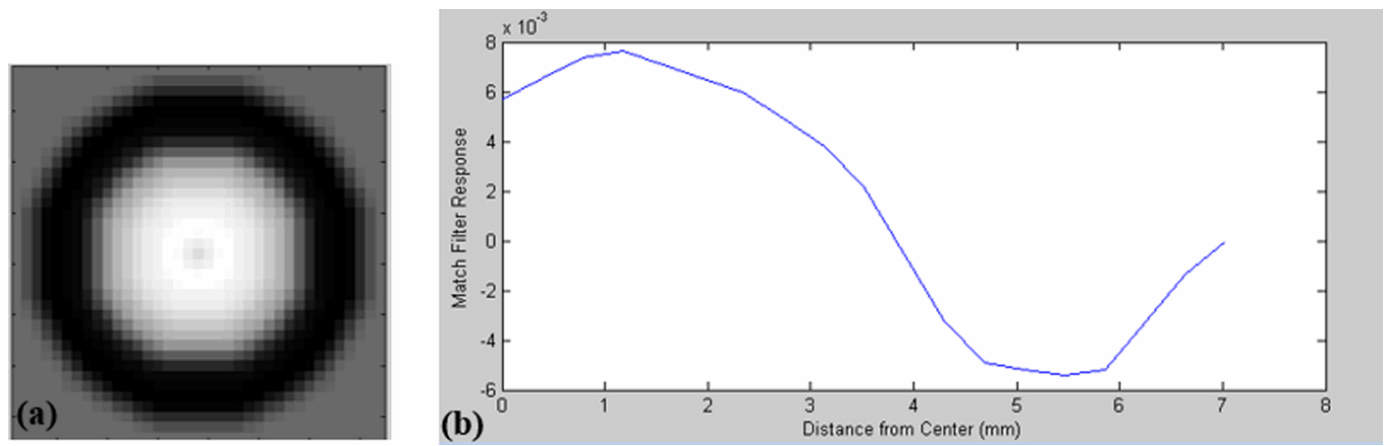

FIG. 4. (a) Matched filter and (b) matched filter value based on distance from the center of the filter.

Medical Physics, Vol 43, No. 1 (January 2016): pg. 324-335. DOI. This article is (C) American Association of Physicists in Medicine and permission has been granted for this version to appear in e-Publications@Marquette. American Association of Physicists in Medicine does not grant permission for this article to be further copied/distributed or hosted elsewhere without the express permission from American Association of Physicists in Medicine. 

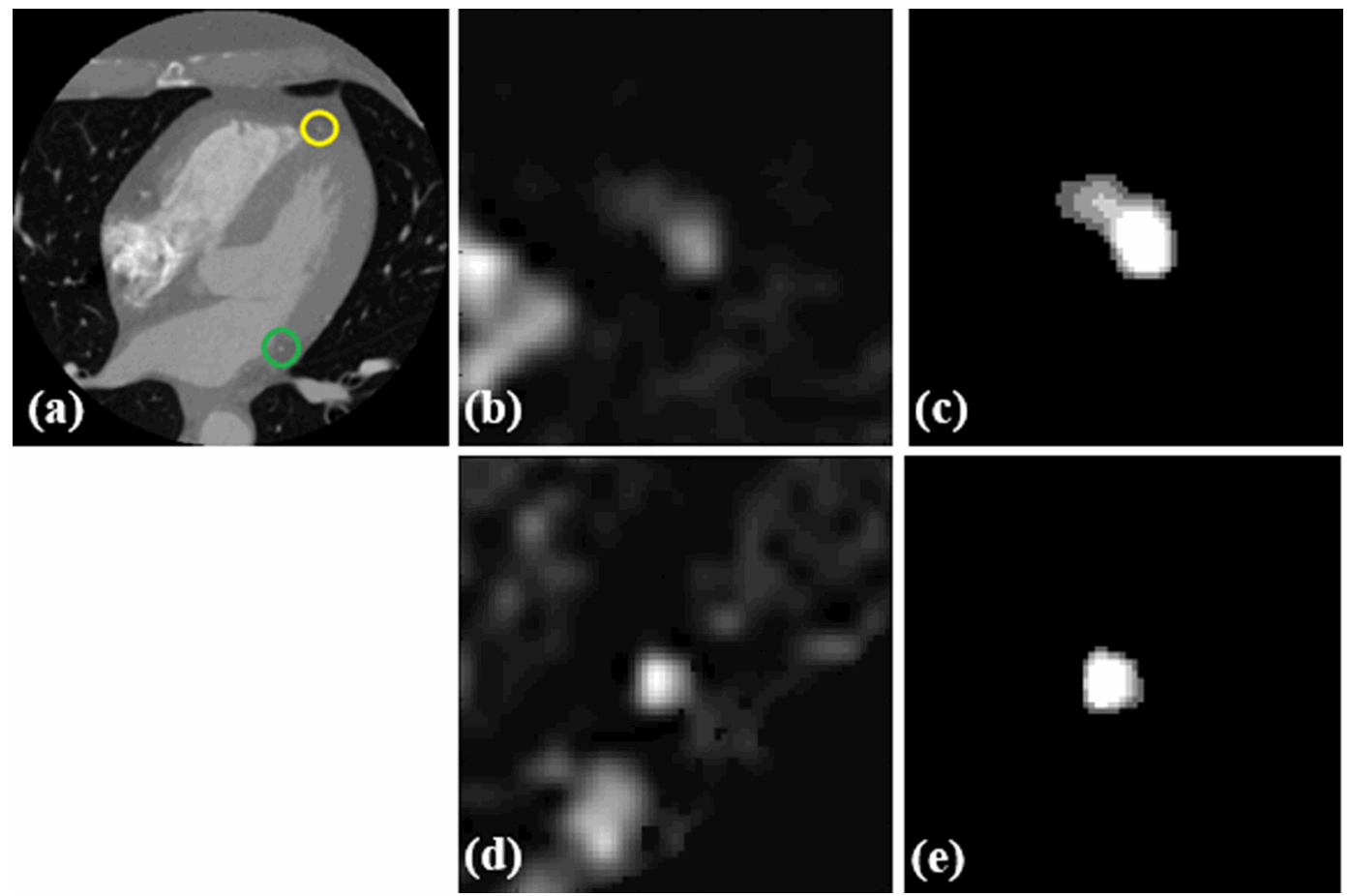

FIG. 5. Examples of circularity scoring: (a) original image with two candidate points circled for the LAD and LCX vessels, (b) ROI in the top hat image near the LAD, (c) thresholded LAD region with circularity score of 0.518 , (d) ROI in the top hat image near the LCX, (e) thresholded LCX region with circularity score of 0.772 .

TABLE I. Summary of the dataset characteristics.

\begin{tabular}{lllll}
\hline & \multicolumn{5}{l}{ Mean Standard deviation Minimum Maximum } \\
BMI & 29 & 5 & 21 & 42 \\
Heart rate (bpm) & 70 & 7 & 60 & 79 \\
Effective dose (mSv) & 5.1 & 3.1 & 0.7 & 11.1 \\
\hline
\end{tabular}
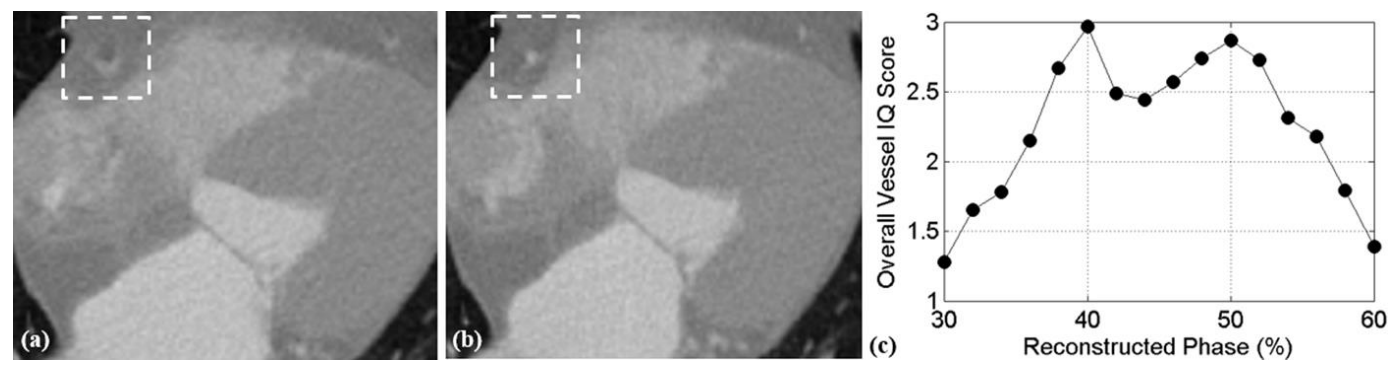

FIG. 6. Axial image reconstructed at (a) the standard end-systole phase of $44 \%$ and (b) the algorithm selected best phase of $40 \%$. The RCA is highlighted for comparison of motion artifacts, which are reduced in the algorithm-selected phase. (c) Overall vessel IQ score calculated by the algorithm for this exam.

Medical Physics, Vol 43, No. 1 (January 2016): pg. 324-335. DOI. This article is (C) American Association of Physicists in Medicine and permission has been granted for this version to appear in e-Publications@Marquette. American Association of Physicists in Medicine does not grant permission for this article to be further copied/distributed or hosted elsewhere without the express permission from American Association of Physicists in Medicine. 

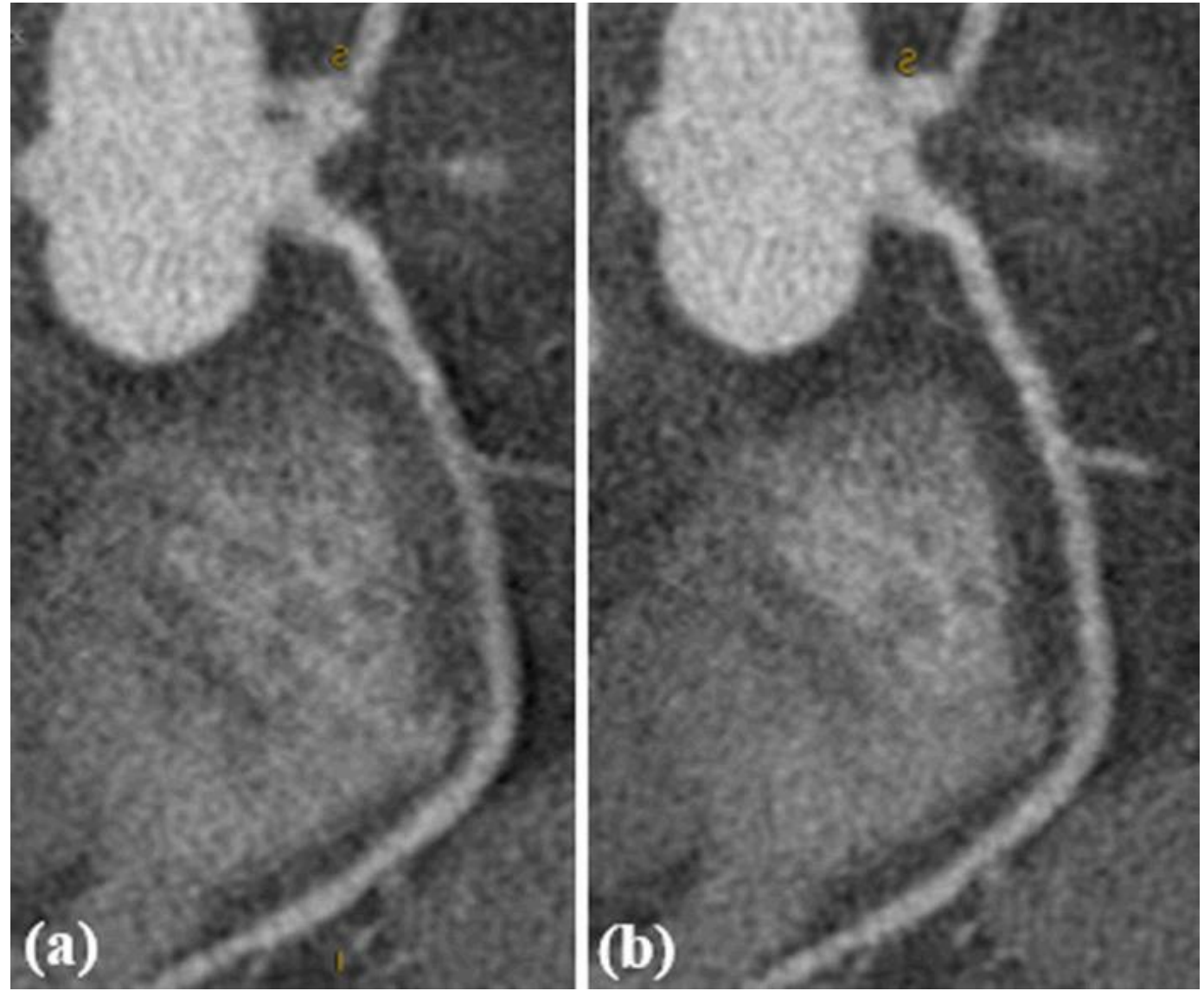

FIG. 7. Reformatted images displaying the RCA reconstructed at (a) the standard endsystole phase of $44 \%$ and (b) the algorithm-selected best phase of $40 \%$.
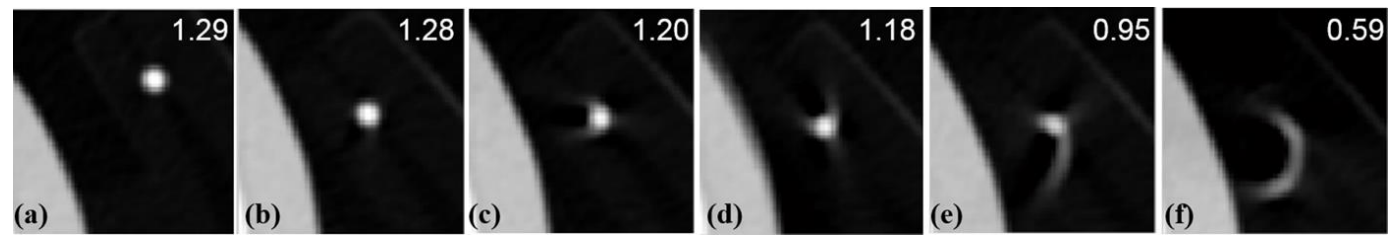

FIG. 8. Phantom images of 2 -mm-diameter iodine tube at velocities of (a) $0 \mathrm{~mm} / \mathrm{s}$, (b) $10 \mathrm{~mm} / \mathrm{s}$, (c) $17 \mathrm{~mm} / \mathrm{s}$, (d), $33 \mathrm{~mm} / \mathrm{s}$, (e) $53 \mathrm{~mm} / \mathrm{s}$, and (e) $65 \mathrm{~mm} / \mathrm{s}$. The circularity score, as described in Eqs. (2) and (3), is displayed for each image.

Medical Physics, Vol 43, No. 1 (January 2016): pg. 324-335. DOI. This article is (C) American Association of Physicists in Medicine and permission has been granted for this version to appear in e-Publications@Marquette. American Association of Physicists in Medicine does not grant permission for this article to be further copied/distributed or hosted elsewhere without the express permission from American Association of Physicists in Medicine. 
NOT THE PUBLISHED VERSION; this is the author's final, peer-reviewed manuscript. The published version may be accessed by following the link in the citation at the bottom of the page.
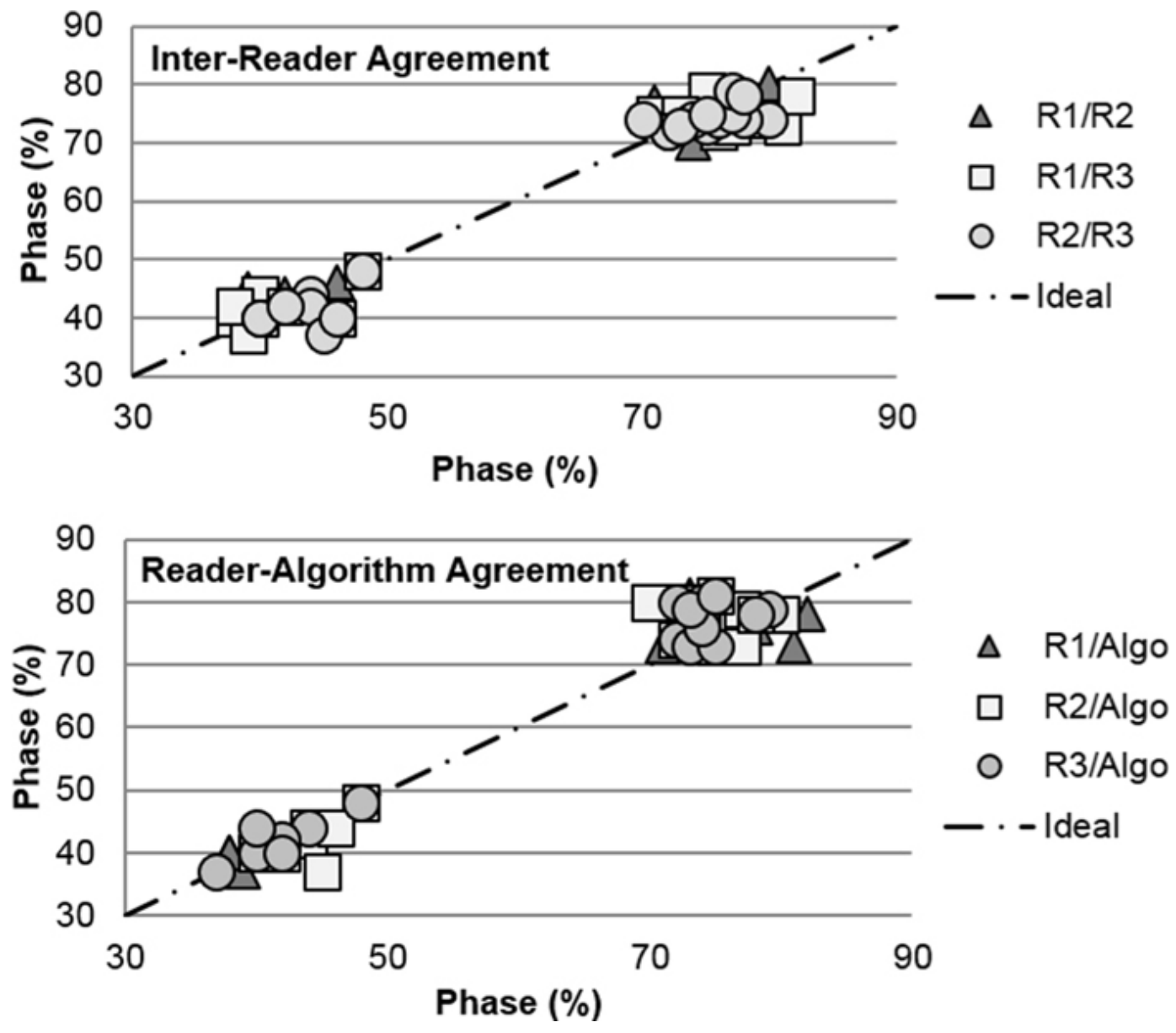

FIG. 9. (Top) Pairwise comparison of inter-reader agreement. Each marker type represents a pair of readers. Each data point plots the phase selected by one reader on the horizontal axis against the phase selected by a second reader on the vertical axis for a single case. The ideal match between readers is plotted as the dashed line. (Bottom) Reader-algorithm agreement plotted for each of the three readers, with the algorithm-selected phases plotted on the vertical axis.

Medical Physics, Vol 43, No. 1 (January 2016): pg. 324-335. DOI. This article is @ American Association of Physicists in Medicine and permission has been granted for this version to appear in e-Publications@Marquette. American Association of Physicists in Medicine does not grant permission for this article to be further copied/distributed or hosted elsewhere without the express permission from American Association of Physicists in Medicine. 
NOT THE PUBLISHED VERSION; this is the author's final, peer-reviewed manuscript. The published version may be accessed by following the link in the citation at the bottom of the page.

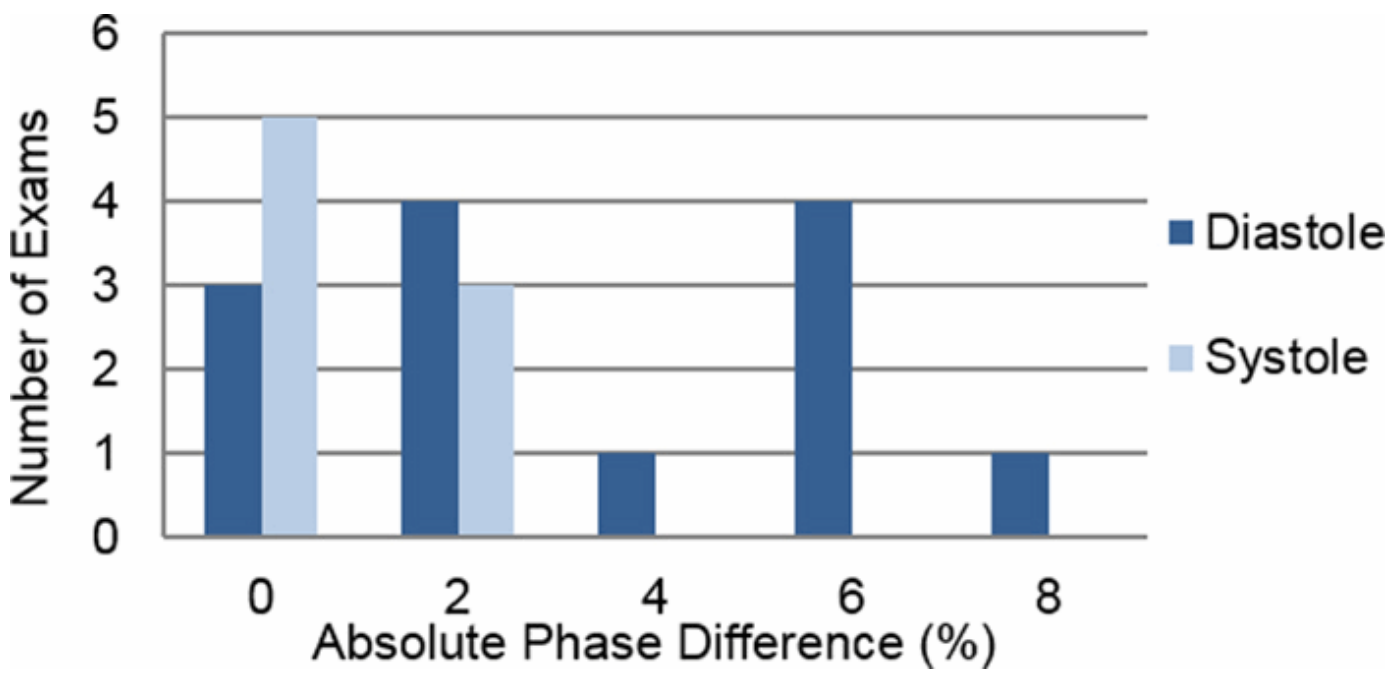

FIG. 10. Histogram of differences between reader consensus and algorithm-selected best phases.

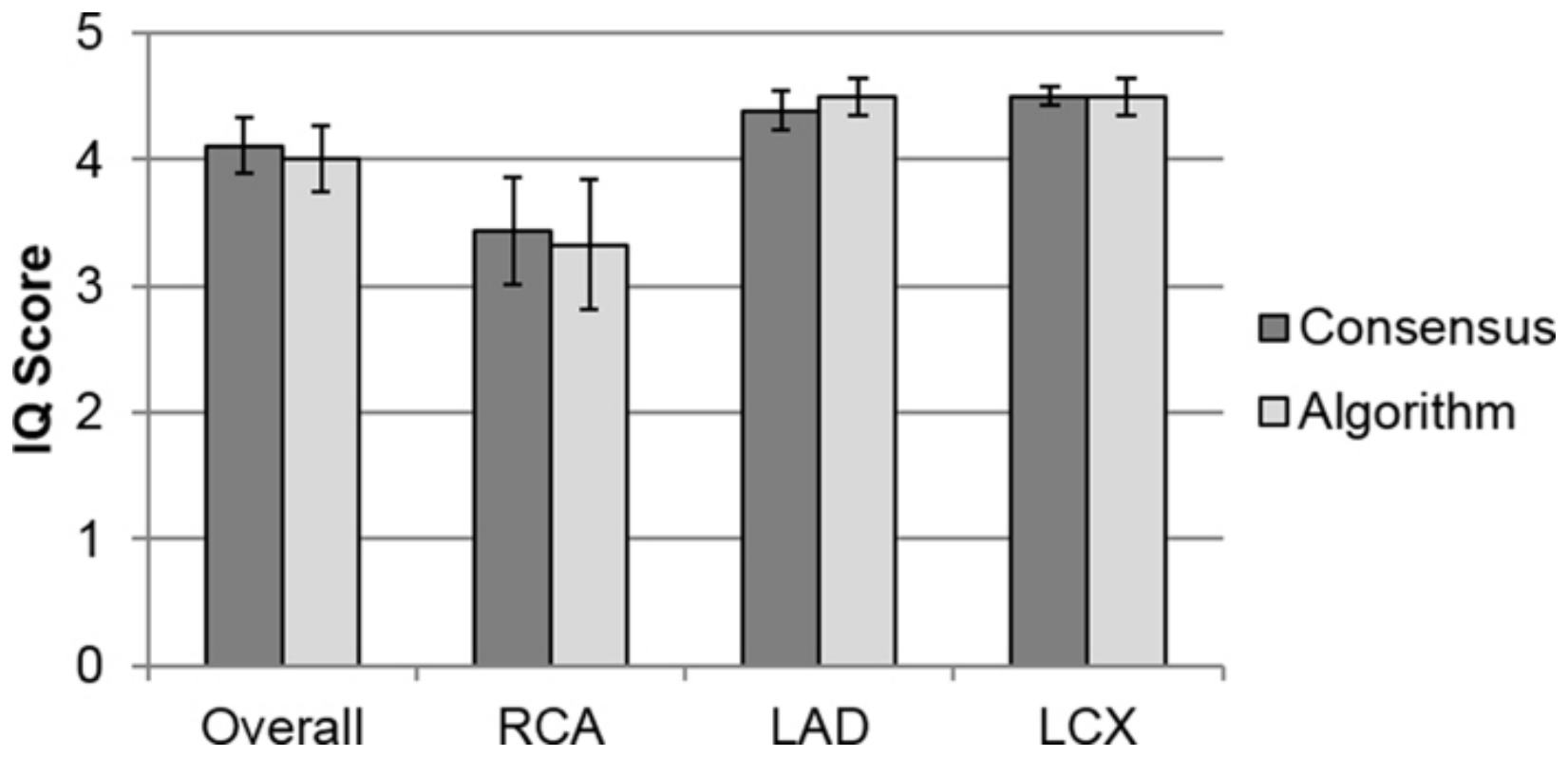

FIG. 11. Subjective image quality scores for images reconstructed at the reader consensus and algorithm-selected best phases for overall image quality and for each of the individual vessels. A score of 5 indicates no apparent motion artifacts and a score of 1 represents nondiagnostic image quality. The error bars depict the standard deviation of IQ scores across readers and cases.

Medical Physics, Vol 43, No. 1 (January 2016): pg. 324-335. DOI. This article is (C) American Association of Physicists in Medicine and permission has been granted for this version to appear in e-Publications@Marquette. American Association of Physicists in Medicine does not grant permission for this article to be further copied/distributed or hosted elsewhere without the express permission from American Association of Physicists in Medicine. 
NOT THE PUBLISHED VERSION; this is the author's final, peer-reviewed manuscript. The published version may be accessed by following the link in the citation at the bottom of the page.
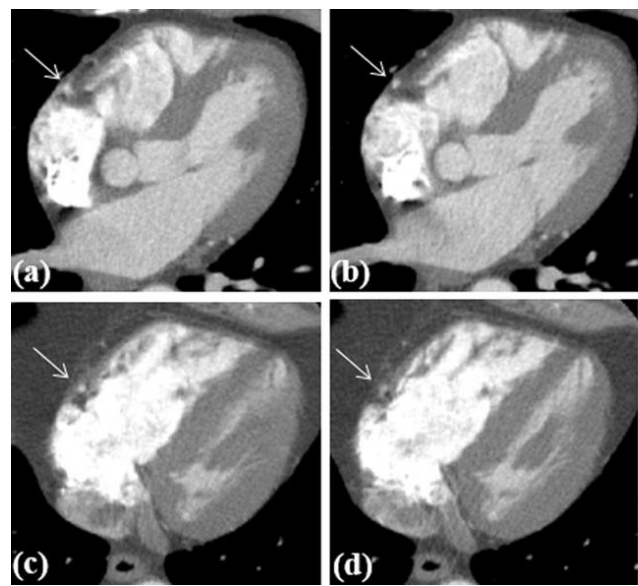

$$
\begin{aligned}
& \text { o } \\
& \text { ơ } \\
& \text { ô } \\
& \text { o } \\
& \text { (e) }
\end{aligned}
$$

-Consensus

口Algorithm

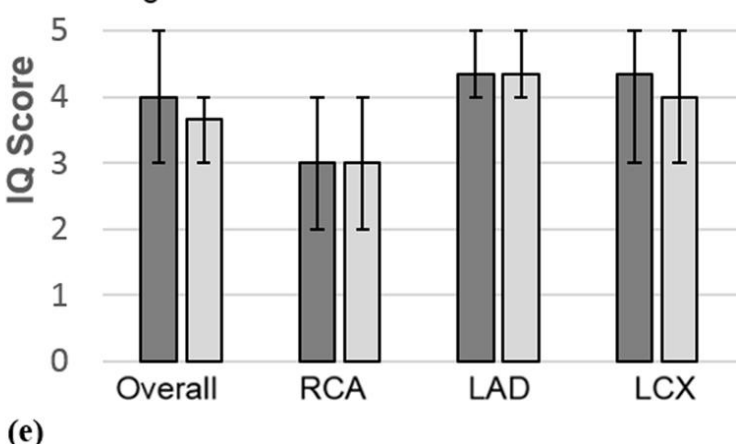

FIG. 12. Reconstructed images at the (a) and (c) consensus best phase of $72 \%$ and (b) and (d) algorithm selected best phase of $80 \%$ for two slice locations. The RCA is depicted with an arrow. (e) Average subjective image quality scores for the consensus and algorithm selected phases for this exam. The error bars represent the minimum and maximum IQ scores across the three readers. This exam represents the largest phase difference between the consensus and algorithm selections.

Medical Physics, Vol 43, No. 1 (January 2016): pg. 324-335. DOI. This article is @ American Association of Physicists in Medicine and permission has been granted for this version to appear in e-Publications@Marquette. American Association of Physicists in Medicine does not grant permission for this article to be further copied/distributed or hosted elsewhere without the express permission from American Association of Physicists in Medicine. 
NOT THE PUBLISHED VERSION; this is the author's final, peer-reviewed manuscript. The published version may be accessed by following the link in the citation at the bottom of the page.

\section{Appendix: Two Dimensional Cardiac Segmentation Algorithm}

This section describes the 2D cardiac segmentation algorithm applied to the axial slices. An algorithm for cardiac segmentation based on an axial slice of the heart was developed because full 3D data may not be available. The steps of the segmentation algorithm are summarized in Fig. 13.
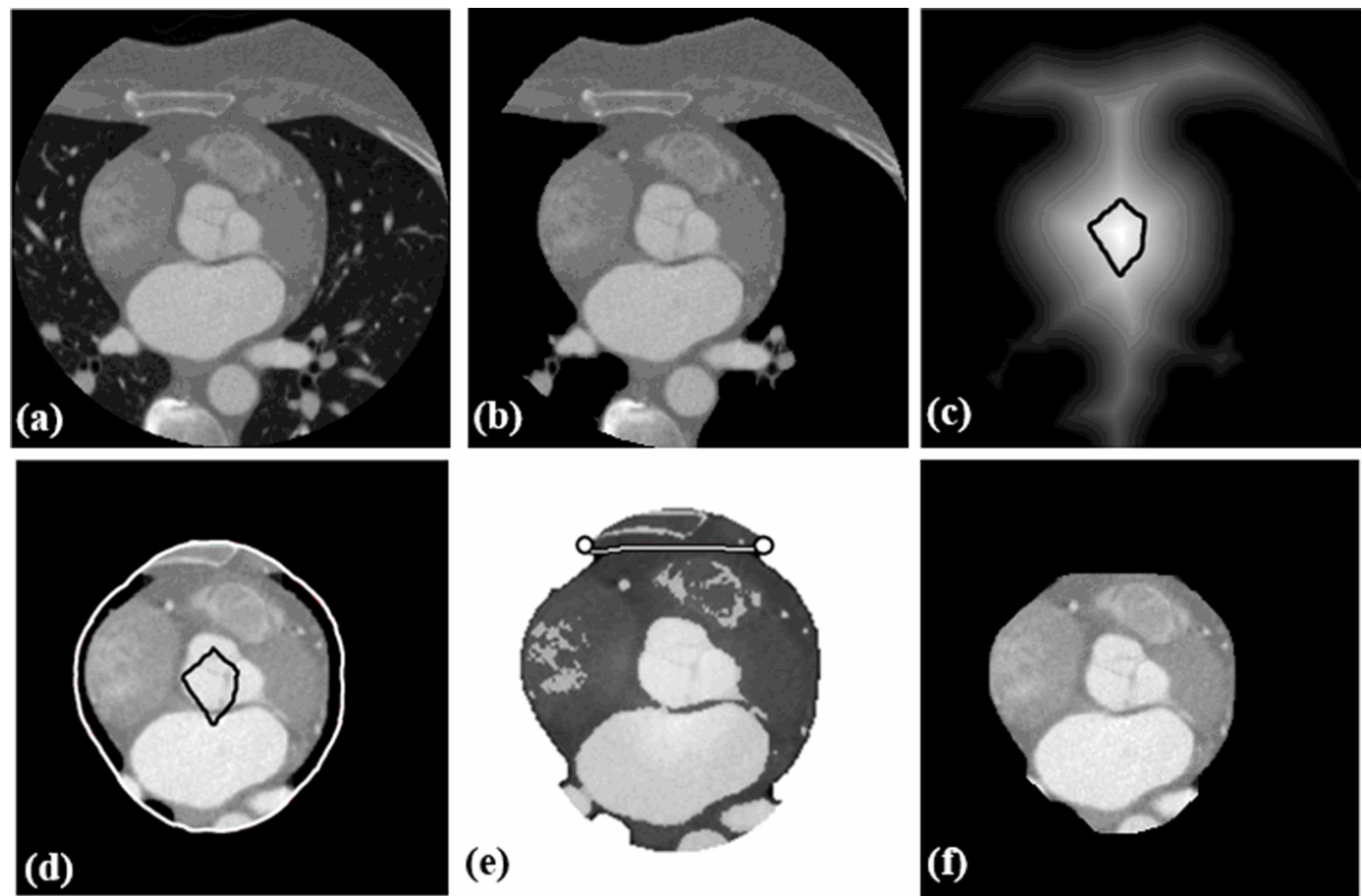

FIG. 13. Steps in the segmentation process: (a) original image, (b) image after lung removal, (c) distances of every point on the image from the lungs. The dark outline shows the central heart region. (d) Initial segmentation of the image with ribs still present. The white outline shows the expansion from the center of the heart. (e) Cost function where the minimum cost path between rib connection points is shown in white. (f) Final segmentation with ribs removed.

\section{Lung removal}

The lungs are identified by applying a threshold to the image, where regions of low CT number are identified as potential lung regions. Regions above the threshold are labeled with a connected-components algorithm using four-connectivity, and the region with the largest area is selected. A morphological closing is performed on the region because shading artifacts can cause values within the cardiac region to fall below the threshold.

\section{Heart-region segmentation}

In this step, the heart contour is identified based on the location of the lungs. The Euclidian distance, D, from any point on the image to the closest point on the

Medical Physics, Vol 43, No. 1 (January 2016): pg. 324-335. DOI. This article is (C) American Association of Physicists in Medicine and permission has been granted for this version to appear in e-Publications@Marquette. American Association of Physicists in Medicine does not grant permission for this article to be further copied/distributed or hosted elsewhere without the express permission from American Association of Physicists in Medicine. 
NOT THE PUBLISHED VERSION; this is the author's final, peer-reviewed manuscript. The published version may be accessed by following the link in the citation at the bottom of the page.

lungs is calculated. The region with distance above a threshold, DThresh, was identified as the center of the heart [Fig. 13(c)] where DThresh is the product of the maximum distance and a scaling factor $a$. The initial heart segmentation includes all values not in the lungs that are within a Euclidian distance of DThresh* $(1+\beta)$ from the central heart region [Fig. 13(d)]. This removes any regions that branch from the center of the heart where $\beta$ is the tolerance for branching regions. In the current algorithm implementation, $\beta=0.15$ and $a=0.8$.

\section{Rib removal}

The ribs are removed by finding points on the right and left sides of the heart where the ribs connect to both the heart and lungs, hereafter referred to as rib connection points. This is only done once per slice because the ribs are expected to be in the same location for each phase. The ribs are identified as regions in the top half of the image that were removed by the initial heart segmentation, are not a part of the lungs, and intersect both the initial segmented region and the edge of the field of view. The lowest and most central points on this region are identified for the right and left sides of the image and labeled as the rib connection points. If no appropriate points can be found, the ribs are not present and the segmentation is complete.

Otherwise, a line is automatically drawn between the rib connection points based on a cost function and all points above it are removed. The initial cost for each pixel in the heart region is equal to the reconstructed CT number. This gives additional cost when passing through chambers of the heart. Points outside the initial heart segmentation are not considered as possible paths for the line. To discourage the path from going through the center of the heart, an image is constructed whose value is the highest in the heart center, defined previously as the region where D > DThresh, and decreases linearly to zero halfway between the center of the heart and the lungs. This image is added to the previously defined cost image. The cost weighted distance is calculated for each rib connection point using a geodesic time algorithm ${ }^{22}$ where the distance between points is calculated using quasi-Euclidian distance, a piecewise variation of Euclidian distance. ${ }^{23}$ The two cost weighted distance functions are summed and the minimum cost path is selected as the pixel with the smallest value for each column between rib connection points. The final segmentation is achieved by including the region below this path and performing a morphological open to smooth the edges of the segmentation [Fig. 13(f)].

Medical Physics, Vol 43, No. 1 (January 2016): pg. 324-335. DOI. This article is @ American Association of Physicists in Medicine and permission has been granted for this version to appear in e-Publications@Marquette. American Association of Physicists in Medicine does not grant permission for this article to be further copied/distributed or hosted elsewhere without the express permission from American Association of Physicists in Medicine. 